\title{
Bienestar: ¿una experiencia subjetiva?
}

\author{
Dámaris Quinteros-Zúñiga*
}

\section{RESUMEN}

El presente trabajo es de revisión bibliográfica y tiene por objetivo la comprensión del bienestar del ser humano como una vivencia positiva, a través de la cosmovisión bíblica y del Espíritu de Profecía. Se extrae un modelo basado en la premisa bíblica del interés divino por el bienestar del ser humano (Jer. 29:11, Sal. 35:27), y la necesidad de comprender y practicar la ley de Dios como condición para el goce de un genuino bienestar (Job: 36:10, Pr. 3:2). Se comprenden dos dimensiones temporales en la experiencia del bienestar, el terrenal y el eterno (Sal. 25:13, HC, 275, HAp, 280), además de cuatro áreas: bienestar físico, mental, social y espiritual, las mismas que se retroalimentan. Los agentes del desarrollo del bienestar así concebido se hallan en el hogar, las escuelas, hospitales u otras instituciones cristianas y en la Iglesia. Desde esta perspectiva se analiza los aportes hallados en la literatura psicológica científica sobre este tema, que concibe al bienestar como una apreciación subjetiva, positiva y global de la vida que perdura a lo largo del tiempo (Diener, 1994). Asimismo, a través de diversos estudios, se resalta la importancia de este constructo ya que guarda correlación y repercute sobre una serie de procesos psicológicos importantes, como la asertividad y rendimiento académico, la resiliencia, el optimismo y la felicidad, entre otros. Se concluye que el estudio del bienestar es de importancia por el rol medular que juega en la existencia del ser humano y que traspasa la subjetividad de quien lo experimenta. Desde el concepto bíblico, el bienestar resulta del cultivo de una relación con el Creador y la observancia de las leyes divinas, generando pensamientos, actitudes y conductas positivos. Solo de esta manera todo hombre y mujer podrán gozar de un pleno bienestar en todas sus dimensiones. Además que el bienestar experimentado en la vida terrenal, bajo los principios de Dios, siendo una antesala del verdadero bienestar eterno el cual debe procurar.

Palabras clave: Bienestar, bienestar subjetivo, psicología positiva, psicología y Biblia.

\begin{abstract}
This paper is a literature review and aims compression human welfare as a positive experience, through the lens of a biblical worldview and the spirit of prophecy. Model is extracted based on the biblical premise divine interest in the welfare of human being (Jer. 29:11, Psalm 35:27), and the need to understand and practice God's law as a condition for the enjoyment of a genuine welfare (Job: 36:10, Proverbs 3:2). They comprise two temporal dimensions in the wellness experience, the earthly and the eternal (Ps. 25:13, HC, 275, HAp, 280), plus 4 areas: physical, mental, social and spiritual that feed them. Development agents and designed well, are in the home, in schools, hospitals or other Christian and church. From this perspective we analyze the contributions found in scientific psychological literature on this subject, being conceived as a subjective, global positive and life that endures over time (Diener, 1994). Also, through various studies, it highlights the importance of this construct as correlates and impact on a number of important physiological processes, such as assertiveness and academic performance, resilience, optimism and happiness, among others. We conclude that the study of well-being is important for the nuclear role it plays in human existence that transcends the subjectivity of who experiences it. From the biblical concept of welfare is cultivating a relationship with the Creator and the observance of the divine laws, which generates thoughts, attitudes and positive behaviors. Only in this way every man and woman can enjoy a full well-being in all its dimensions. In addition to the well-being experienced in earthly life the principles of God are a prelude to the true eternal welfare which should endeavor.
\end{abstract}

Keywords: Welfare, subjective well, positive psychology, psychology and Bible.

*Correspondencia:damaris@upeu.edu.pe, 51-1-989059479 


\section{INTRODUCCIÓN}

En la interacción cotidiana las personas suelen preguntar: “¿cómo estás?”. Y la respuesta parece ser tan sencilla y automática que suena como una muletilla: "bien". Pero ¿qué significa realmente estar o sentirse "bien"? Esta experiencia de bienestar representa para algunos la ausencia de preocupaciones o de dolores corporales, verse bien frente al espejo, no tener aprietos económicos o estar progresando en el trabajo y la vida profesional. De modo que autores como Diener (1994), Casullo y Castro (2000), García (2004) y Carr (2007) han coincido en concebirla como un "bienestar subjetivo".

Carr (2007) explica que el objetivo de la psicología positiva es comprender la felicidad y bienestar subjetivo. Así, la felicidad y el bienestar se refieren a "sensaciones positivas como la alegría o la serenidad y a estados positivos como los que suponen la fluidez o la absorción" ( 23).

Para Diener (1994) el bienestar psicológico está relacionado con su medición y reconoce en ella tres características: subjetividad, presencia de indicadores positivos (y no solo la ausencia de factores negativos) y una valoración global de la vida. Así, un alto bienestar depende de una apreciación positiva de aquella que perdura a lo largo del tiempo, y el bajo bienestar depende del desajuste entre expectativas y logros. Esta definición coincide con la de Casullo y Castro (2000) quienes consideran al bienestar psicológico como el grado en que un individuo juzga su vida "como un todo" en términos favorables.

Gómez, Villegas de Posada, Barrera y Cruz (2007) conciben al bienestar subjetivo como lo que las personas piensan y sienten con respecto a su vida y las conclusiones que sacan cuando evalúan su existencia. Y que, en un sentido más estricto, la felicidad se puede concebir como parte del bienestar subjetivo, ya que este hace referencia al juicio global que hacen las personas de su propia vida y que esta evaluación es tanto cognoscitiva como afectiva.

Para García (2004) se trata de una vivencia subjetiva relativamente estable que se da en relación a un juicio de satisfacción con la vida (balance entre expectativas y logros) en las áreas de mayor significación para cada individuo. El bienestar así definido, posee carácter positivo, de disfrute personal, de estados emocionales positivos. Además que el bienestar psicológico tiene elementos vinculados a la esfera emocional, y otros que son expresión de lo cognitivo-valorativo. Estos aspectos estarían relacionados e influenciados por la personalidad, así como por las circunstancias medioambientales y la historia personal. Esta autora añade que el bienestar psicológico está determinado socioculturalmente, existiendo una "interrelación dialéctica entre lo biológico, social y psicológico, donde la personalidad, como sistema regulador, desempeña un importantísimo papel” (p.9).

De estas concepciones sobre el bienestar global, que incluye al psicológico, llama la atención la reiteración de su carácter subjetivo, centrado en la propia interpretación, balance, valoración o la conclusión del juicio de bienestar que cada individuo realiza en base a sus experiencias, su contexto sociocultural o sus expectativas.

Sin embargo, desde la cosmovisión bíblica, el juicio humano es imperfecto e incompleto cuando, lejos de afirmarse en los principios divinos, persigue su propia noción de felicidad y de plenitud vital (Sal 94:11, Sal 139: 23-24 y 1 Cor 3: 19-23). Si se deja de lado el temor a Dios y el respeto por sus leyes, se puede caer en una tergiversación del bienestar o en una comprensión limitada de ella, ya que el plan de Dios para la vida del ser humano es superior (Sal 139:17, Pro 16:3 y Heb 4:12). Asimismo, en Isaías 55:8 y 9, se afirma: "Porque mis pensamientos no son vuestros pensamientos, ni vuestros caminos son mis caminos, dice Jehová. Como son más altos los cielos que la tierra, así mis caminos y mis pensamientos más altos que vuestros pensamientos".

Frente a ello, surge la necesidad de comprender la naturaleza y los fundamentos del bienestar a la luz de la Biblia y del Espíritu de Profecía, dado a través de los escritos de Elena White y analizar los conocimientos y aportes actuales al tema.

Mediante el bienestar, desde la cosmovisión bíblica, Jehová busca el bienestar de sus hijos. Es fácil para el ser humano angustiarse, desanimarse y desesperanzarse frente a situaciones problemáticas, experimentando así estrés ansiedad, desánimo y desconfianza.

Esta situación agobiante experimentó el pueblo hebreo cuando estuvieron desterrados en Babilonia, extrañando su hogar, sus tierras y los momentos prósperos vividos en su lugar de origen. Hecho que concordaba con una anterior profecía de Dios, cuando anunció que debido a la desobediencia e idolatría de la nación hebrea, esta sería sometida por el ejército de Nabucodonosor y llevada en cautiverio.

Frente a ello, Jeremías transmite este mensaje de Dios: "Porque yo sé los planes que tengo para vosotros, dice Jehová, planes de bienestar (shalom) y no de mal, para daros porvenir y esperanza" (Jer 29:11). Este mensaje forma parte de una promesa divina que 
se cumpliría cuando el remanente de los expatriados retornase de Babilonia, después de los setenta años de cautiverio.

Las diferentes versiones de la Biblia traducen la palabra original shalom en términos como paz (Biblia de Jerusalén, 1980 y Reina Valera, 1960), bienestar (Dios Habla Hoy, 1995) y prosperidad (Libro del Pueblo de Dios, 1980).

Nichol (1985), en el Comentario Bíblico Adventista del Séptimo Día, explica que el término shalom representa todo lo bueno que la vida puede ofrecer que, además de paz, también significa salud, prosperidad, bienestar y amistad. De modo que esta promesa señalaba que "si para hacer justicia el Señor tuvo que herir a sus hijos con el cautiverio, su amor y misericordia los sanaría, haciéndolos regresar a su patria", 491.

White explica que "...Dios permite que las pruebas asedien a su pueblo para que, mediante su constancia y obediencia, puedan enriquecerse espiritualmente, y para que su ejemplo sea una fuente de poder para otros...Los sufrimientos que prueban tan severamente la fe y que nos hacen pensar que Dios nos ha olvidado, sirven para llevarnos más cerca de Cristo, para que echemos nuestras cargas a sus pies y experimentemos la paz que nos ha de dar en cambio" (pp. 122).

Este hecho contradice la perspectiva humana que considera al hombre como echado a su suerte, que lucha solo por lograr prosperidad en búsqueda de su bienestar. El ser humano no está solo. Dios tiene un plan de vida para él, y ese plan implica ventura. Así, David declara: "Sea ensalzado Jehová, que se complace en el bienestar de su siervo" (Sal 35:27).

A pesar de las lecciones duras necesitaba aprender Israel, Dios siempre estuvo cuidando y velando por el bienestar de sus hijos. Y ese mensaje es tan válido para el hombre y la mujer de hoy, como lo fue para ese pueblo. Pues Dios desea que el ser humano prospere, experimente gozo, tenga un provenir fructífero y tenga esperanza.

Por otro lado, White enfatiza la importancia la gratitud y de valorar las bendiciones de Dios, aún las más pequeñas, en lugar de centrarse en las dificultades y ser desconfiados. Menciona en este contexto que "todo el cielo está interesado en nuestro bienestar" (CC, 122). Por lo tanto, el ser humano debe confiar sus cargas a Dios y permanecer sereno, alegre, de buen ánimo y confiado en Aquel que todo lo puede. Dios tiene un plan para el ser humano, este no anda a la deriva, ese plan es de bienestar, de modo que el verdadero bienestar del cada ser humano Dios los conoce, él ya lo sabe.

\section{Fundamentos del bienestar}

Se parte de la premisa de que la experiencia de bienestar está vinculada al temor de Jehová y a la observancia de la ley de Dios. Lo que se reconoce cuando Elihú le recuerda a Job que los que escuchan y sirven a Jehová "acabarán sus días con bienestar y sus años con prosperidad" (Job 36:10). También el rey David escribió que el alma del que teme a Jehová "reposará en bienestar, y sus descendientes heredarán la tierra" (Sal 25:13). Igualmente, el sabio Salomón señala que "abundancia de días y años de vida y bienestar te aumentarán" al guardar la instrucción y los mandamientos en el corazón (Pr 3:2).

Asimismo, White explica que "el bienestar del hombre está vinculado con la soberanía de Dios" y que cuando estamos en relación con la gloria de Dios "procuramos para nosotros mismos el mayor bien que nos es posible recibir" (JT, 328).

Como se ve, los que atienden y ponen en práctica los principios bíblicos y la ley de Dios experimentan mayor plenitud en su vida. Evidentemente este bienestar incrementa las ganas de vivir, la esperanza, la prolongación del tiempo de vida y producirá una experiencia de los años póstumos de ella, con satisfacción.

Además, guardar los principios y la ley divina no solo asegura en bienestar que el ser humano experimenta en la tierra, sino que lo prepara para el bienestar eterno, que solo heredarán los fieles a Dios.

La palabra de Dios también advierte un concepto errado de bienestar, tal cual lo presenta el enemigo de Dios, el que se basa en riquezas, poder, placeres, honores y supuesta felicidad, bajo la estrategias de la deshonestidad y el egoísmo. "Pero él ofrece lo que no puede otorgar" (DTG, 104) ya que solo "Dios es la fuente de todo bienestar y consuelo" $(\mathrm{CN}, 137)$.

Además, White explica que el propósito original de Dios para los seres humanos era que se amaran y respetaran mutuamente, que existiera interés puro y desprendido en el bienestar mutuo. Pero que el egoísmo, la ambición y el amor propio han generado indisposición y discordia.

Sin embargo, siguiendo el consejo bíblico, se requiere que vindiquen esas relaciones, con el objetivo del bienestar mutuo. 
Ello se refleja en la carta que Jeremías envió a los ancianos que estaban cautivos en Babilonia, allí les da esta recomendación: "Procurad el bienestar de la ciudad... rogad por ella, porque es su bienestar tendréis vosotros bienestar" (Jer 29:7). Evidenciando que el pueblo de Dios debía ser de influencia positiva a los pobladores de las ciudades donde ellos se encontraran.

Así, "el bienestar de la sociedad, el éxito de la Iglesia, la prosperidad de la nación, dependen de las influencias que reinan en el hogar" (CM, 328), de la educación física y moral que los miembros de la familia reciben.

De allí la importancia de gobernar a la familia bajo principios y desde una perspectiva de la vida fundamentada de la Biblia que permita a los miembros de la sociedad desarrollar actitudes y comportamientos proactivos, corteses y considerados por el bienestar de sus semejantes, en la sociedad y en la iglesia.

\section{Enfoques sobre el bienestar}

A continuación se describen algunos modelos psicológicos sobre el bienestar subjetivo, para luego presentar el enfoque bíblico y analizarlos desde esta perspectiva.

\section{Modelos descriptivos del bienestar subjetivo}

Dentro del campo de la psicología actual, se encuentran modelos sobre el bienestar subjetivo, los que se describen a continuación y se visualizan en la tabla 1:
Teoría de Deci y Ryan (1985) identificada como la teoría de la autodeterminación y en concordancia con la postura de Rogers. Propone que el bienestar psicológico es fundamentalmente consecuencia de un funcionamiento psicológico óptimo con un funcionamiento psicológico sano, basado en una adecuada satisfacción de las necesidades psicológicas básicas y un sistema de metas congruente y coherente.

Modelo de Ryff (1989), considerada como uno de los eslabones fundamentales de la psicología positiva, concibeal bienestar psicológico como un concepto multidimensional, proponiendo seis pilares: control ambiental, desarrollo personal, autodeterminación, autonomía, autoaceptación y relaciones positivas con otros.

Modelo de Diener (1994), el bienestar subjetivo implica la satisfacción con la vida en general y con diversos dominios, así como también la preponderancia de un estado de ánimo positivo. En su criterio, se puede pensar en cuatro componentes separables: la satisfacción con la vida (el juicio global acerca de la propia vida), el afecto positivo (la experiencia de muchas emociones y estados positivos), el afecto negativo (la experiencia de pocas emociones desagradables), la satisfacción con dominios importantes de la propia vida (por ejemplo, el trabajo).

Modelo de Seligman (2003), que propone un marco identificado como el modelo de las tres vías hacia la felicidad, desde el cual pretende mostrar los caminos que conducen al bienestar y la felicidad: la vida placentera, la vida comprometida hacia el desarrollo de experiencias óptimas y la vida significativa basada en el logro de objetivos trascendentes. 
Tabla 1

Modelos teóricos explicativos del bienestar subjetivo

\begin{tabular}{|c|c|c|c|}
\hline Modelo & Estructura & Dimensiones & Descripción \\
\hline \multirow{2}{*}{$\begin{array}{r}\text { Deci } \\
\text { y Ryan } \\
(2000)\end{array}$} & Necesidades & $\begin{array}{l}\text { Necesidades psicológicas } \\
\text { básicas }\end{array}$ & $\begin{array}{l}\text { Satisfacción de necesidades de autonomía, } \\
\text { competencia y vinculación o relaciones }\end{array}$ \\
\hline & $\begin{array}{l}\text { psicológicas básicas } \\
\text { y superiores. }\end{array}$ & $\begin{array}{l}\text { Sistema de metas } \\
\text { congruente }\end{array}$ & $\begin{array}{l}\text { Metas intrínsecas más que extrínsecas, coherentes } \\
\text { con los propios valores e intereses }\end{array}$ \\
\hline \multirow{6}{*}{$\begin{array}{c}\text { Carol } \\
\text { Ryff (1989) }\end{array}$} & \multirow{6}{*}{$\begin{array}{l}\text { El bienestar } \\
\text { subjetivo como } \\
\text { constructo } \\
\text { multidimensional }\end{array}$} & Control ambiental & $\begin{array}{l}\text { Capacidad para controlar en forma efectiva el } \\
\text { medio y la propia vida }\end{array}$ \\
\hline & & Desarrollo personal & $\begin{array}{l}\text { La creencia de que la vida tiene propósito y } \\
\text { significado }\end{array}$ \\
\hline & & Autodeterminación & $\begin{array}{l}\text { Sentido de autodeterminación y propósito en la } \\
\text { vida }\end{array}$ \\
\hline & & Autonomía & $\begin{array}{l}\text { Sentimientos positivos hacia el crecimiento y la } \\
\text { madurez }\end{array}$ \\
\hline & & Autoaceptación & Una apreciación positiva de sí mismo \\
\hline & & $\begin{array}{l}\text { Relaciones positivas con } \\
\text { otros }\end{array}$ & $\begin{array}{l}\text { Capacidad para manejar con eficiencia los } \\
\text { vínculos interpersonales }\end{array}$ \\
\hline \multirow{4}{*}{$\begin{array}{l}\text { Diener } \\
(1994)\end{array}$} & \multirow{4}{*}{$\begin{array}{l}\text { Cuatro } \\
\text { componentes } \\
\text { separables }\end{array}$} & Satisfacción con la vida & Juicio global acerca de la propia vida \\
\hline & & Afecto positivo & $\begin{array}{l}\text { Experiencia de muchas emociones y estados } \\
\text { positivos }\end{array}$ \\
\hline & & Afecto negativo & Experiencia de pocas emociones desagradables \\
\hline & & $\begin{array}{l}\text { Satisfacción con dominios } \\
\text { importantes de la propia } \\
\text { vida. }\end{array}$ & por ejemplo el trabajo o la familia \\
\hline \multirow{3}{*}{$\begin{array}{l}\text { Seligman } \\
(2003)\end{array}$} & \multirow{3}{*}{$\begin{array}{l}\text { Tres vías hacia } \\
\text { el bienestar y la } \\
\text { felicidad }\end{array}$} & La vida placentera & $\begin{array}{l}\text { Incremento de las emociones positivas sobre el } \\
\text { pasado, el presente u el futuro }\end{array}$ \\
\hline & & La vida comprometida & $\begin{array}{l}\text { Práctica cotidiana de las fortalezas personales } \\
\text { con el fin de desarrollar un mayor número de } \\
\text { experiencias óptimas }\end{array}$ \\
\hline & & La vida significativa & $\begin{array}{l}\text { Sentido vital y desarrollo de objetivos que van más } \\
\text { allá de uno mismo. }\end{array}$ \\
\hline
\end{tabular}

Fuente de elaboración propia 


\section{Enfoque bíblico sobre el bienestar}

Se parte de la noción de un ser humano creado a imagen de Dios y de un modo integral; es decir, con aspectos peculiares que deben desarrollarse o cultivarse y equilibrarse para un desarrollo pleno. Así, en Luc 2: 52, al describirse el desarrollo armonioso de Jesús, se dice que "crecía en sabiduría, estatura y en gracia para con Dios y los hombres". Asimismo, en 1 Tes 5:23 se halla este texto: "y el mismo Dios de paz os santifique por completo; y todo vuestro ser, espíritu alma y cuerpo, sea guardado irreprensible para la venida de nuestro Señor Jesucristo". White también describe al ser entero como espíritu, alma y cuerpo (5TI, 492) y como naturaleza intelectual, física y moral (CPI, 88), además añade que un área influye y retroalimenta a otra.

Igualmente, los escritos de White $^{1}$ permiten delimitar cuatro áreas del bienestar y se influyen entre sí. Por ejemplo, explica que "el bienestar físico, mental y moral del hombre hace necesaria una vida de trabajo útil" (CMC, 126). Y en otros textos se añade al bienestar social (DTG, 565, ED, 137). De modo que las áreas identificadas vendrían a ser:

\section{Bienestar fisico}

White explica que "todo órgano del cuerpo y toda facultad de la mente son dones de un Dios bueno y sabio" y que deben ser usados cuidadosamente para dar gloria a Dios (CM, 119); y que el ser humano debe preservarse de prácticas dañinas. Esto implica:

Un estilo de vida saludable (ED, 38).

Mantener un equilibrio entre los plazos de trabajo, sueño, descanso, recreación y ejercicio físico $(\mathrm{HC}$, 448).

Una vida de trabajo útil (CMC, 126) (ED, 44).

Una alimentación adecuada, así como el beber y el vestir (CRA, 5, CM, 120).

Se añade la importancia de elegir un lugar adecuado para establecer un hogar (HC, 448), lo que implica considerar el clima, geografía, espacios para la recreación de la familia.

Estos aspecto refrendan lo que señala las escrituras en 1 Corintios 10:31 "Si, pues coméis o bebéis o hacéis otra cosa, hacedlo para la gloria de Dios".

\section{Bienestar mental}

White manifiesta que "las mentes no santificadas pierden de recibir la energía y el bienestar que Dios ha provisto para ellas. Se muestran inquietas y las acosa un fuerte deseo de experimentar algo nuevo, algo que las gratifique, alague y excite; y a esto lo denominan placer" (EJ, 256), por ello se resalta la importancia de la santificación de las facultades del ser humano (1 Tes 5:23).

\section{Ello conlleva a:}

El desarrollo de una adecuada disciplina para la formación de hábitos sanos (CM, 107) (HC, 275)

Consideran que el bienestar, la felicidad, la vida religiosa, la prosperidad y la piedad dependen de una educación religiosa y de maestros cristianos de normas elevadas, cuyas vidas y ejemplo sean purificados por Dios (CM, 483) (CJE 14.1, CM 328:3, EC 260.3, 2JT 214.2, CM 487.3, CRA 5.1).

La Lectura de la Biblia para cultivar un "intelecto santificado" que favorece el control de experiencias negativas como la angustia y la desesperanza (HC, 275).

Cultivar de emociones positivas como el optimismo, alegría, simpatía y buen humor que favorece el control de experiencias negativas como la angustia y la desesperanza (HC, 392).

Practicar la sencillez y abnegación, altruismo (1 MCP, 244).

Dominio propio y el disfrute de las cosas pequeñas o sencillas (CM, 121).

\section{Bienestar social}

Cuando Cristo abrevió los mandamientos, señaló dos aspectos importantes: el amor a Dios por sobre todas las cosas y el amor al prójimo (Mar 12:29-31). Así mismo, White explica que las enseñanzas bíblicas buscan la prosperidad y el bienestar de la sociedad y la familia $(\mathrm{CN}, 480)$. Esto involucra descentrarse de uno mismo y practicar el servicio a los demás manifestando interés por el bienestar de otros. Implica:

La testificación (3 JT, 62) 565)

Realizar "obras de amor y misericordia" (DTG,

Trabajar por los vecinos y la comunidad, visitar sus hogares manifestando interés por su bienestar, orar por ellos y compartirles el estudio de la palabra de Dios $(\mathrm{MC}, 110)$

Reconocer a la familia, las escuelas y otras instituciones cristianas de atención social como agentes importantes para la generación del bienestar de sus miembros y de la comunidad. 


\section{Bienestar espiritual}

La experiencia del bienestar también tiene un aspecto espiritual. White señala que "solo cuando es impartida la vida espiritual, se encuentra descanso y bienestar permanente", y que ello genera seguridad (5TS, 125). Esto se refrenda con el texto bíblico de Mat 11:28-30 que registra estas palabras de Cristo "Venid a mí todos los que estáis trabajados y cargados, que yo os haré descansar". El relacionamiento con Dios genera bienestar espiritual, y de las demás áreas ya descritas. Porque él es la fuente de bienestar y paz.

\section{La dimensión espiritual implica:}

Mantener una vida religiosa basada en el temor de Dios y de respeto de las leyes morales de Dios (CM, 487)

Practicar la oración y el canto sagrado y el estudio de la palabra de Dios que vivifica y activas las energías de la mente y brinda sabiduría (ED, 45, ED, 44, MJ, 112).

Estudiar, memorizar y repetir promesas de la Palabra de Dios y la testificación de un Salvador compasivo capaz de restituir el descanso mental que se necesita (CM, 466).

Considerando la relevancia de la interacción de estas áreas, se encuentra que el bienestar psicológico o bienestar mental, recibe la influencia del desarrollo físico, social y espiritual. Y desde la perspectiva bíblica el relacionamiento con Dios y el respeto de sus principios son el fundamento de todas ellas.

A diferencia de las posturas psicológicas actuales sobre el bienestar humano, la postura bíblica basa su comprensión en el reconocimiento de Dios como fuente y principio de la dicha, la paz y la seguridad humana, presentando a un Dios preocupado e implicado en el bienestar de sus hijos. Y que además define leyes $\mathrm{y}$ principios de vida que protegen al ser humano del sufrimiento. Igualmente se considera que el respeto a los mismos tanto en el campo físico, social, mental y espiritual apunta al bienestar temporal y eterno. Este último aspecto temporal del bienestar se describe el siguiente apartado.

\section{Dimensiones temporales del bienestar}

Se extrae de la Biblia y de las obras de White dos dimensiones temporales en la experiencia del bienestar, el terrenal o presente y el bienestar eterno.
Bienestar presente o terrenal: se explica que el ser humano debe ocuparse de su bienestar temporal y el de su familia, a través de un estilo de vida saludable o un trabajo digno y que cubra sus necesidades básicas y de desarrollo. Pero también que debe confiar en un Dios que se preocupa del bienestar terrenal del ser humano, brindándole conocimiento a través de su Palabra y supliendo sus necesidades (HAp, 418). Aunque se reconoce la trascendencia del bienestar temporal, se destaca la importancia de que el ser humano considere su bienestar futuro. (HA 280, EC 235, HC 275, RJ 171).

Bienestar futuro o eterno: para ello se requiere de una visión espiritual clara para poder valorar las realidades de la eternidad (CMC, 142). Asimismo, "nuestro bienestar eterno depende de un entendimiento exacto de la ley de Dios, una convicción profunda de su santo carácter y una obediencia lista a cumplir sus condiciones" haciendo su voluntad, se añade que el bienestar eterno depende del "uso de nuestro tiempo, nuestra energía y nuestra influencia" sobre otras personas y nuestra fidelidad a Dios (SSJ, 61), además del desarrollo de un carácter correcto.

La comprensión de estos aspectos temporales, permiten una visión aún más completa de la experiencia del bienestar, trascendiendo lo vivido en la tierra, y extendiéndose hacia la eternidad, tal como se lee en Sal 16:11 "En tu presencia hay plenitud de gozo, delicias en tu diestra para siempre".

Ninguno de los modelos psicológicos seculares revisados incluye esta dimensión de eternidad, ni la concepción bíblica del ser integral. Aspectos, que hacen al enfoque bíblico trascendente y íntegro, ya que la cosmovisión bíblica habla de la intención y un plan divino de restaurar al ser humano y de darle vida eterna, donde podrá gozar del bienestar genuino e imperecedero. Así se registra en Jn 3:16 "Porque de tal manera amó Dios al mundo, que ha dado a su hijo unigénito, para que todo aquel que en él crea, no se pierda, mas tenga vida eterna.

\section{Aspectos vinculados al bienestar psicológico}

A través de diversos estudios científicos se ha encontrado que el bienestar psicológico guarda relación con una serie de procesos psicológicos, tales como la asertividad y rendimiento académico (Asili y Pinzón, 2003; Chávez, 2006 Vásquez, Montgomeri y Montero, 2008), la resiliencia, el optimismo y la felicidad (Salgado 2009), el afrontamiento al estrés (Gonzáles, Montoya, Casullo y Bernabéu, 2002 y Figueroa, Contini, Levín y Estévez, 2003) la satisfacción familiar y el sentido de la vida 
(Villarrubia, García y Rollán, 2005), autoeficacia y satisfacción con la vida (Gómez, Villegas, Barrera y Cruz, 2007), valores y conducta de voluntariado (Valenzuela , 2005) y finalmente con la adaptación social (Fierro 2006).

Mientras que el bienestar psicológico se relaciona negativamente con procesos nocivos como el síndrome del "quemado laboral” (Salas 2010), ansiedad, depresión y neocriticismo (Fierro, 2006) y sobreprotección parental (Asili y Pinzón, 2003).

Además de lo señalado, Gómez, Villegas de Posada, Barrera y Cruz (2007) resumen una serie de investigaciones revisadas y relacionan al bienestar con los siguientes ámbitos:

Pareja: las personas casadas reportan un mayor bienestar subjetivo que las que nunca se casaron, están divorciadas, separadas o son viudas.

Amigos y relaciones sociales: quienes tienen más amigos o quienes pasan más tiempo con ellos tienden a ser más felices. Es decir, quienes disfrutan de más y mejores relaciones sociales, específicamente de amistad, expresan más bienestar.

Trabajo: las personas desempleadas tienen un nivel más alto de tensión, presentan una menor satisfacción con la vida y tasas más altas de suicidio que las personas empleadas.

Salud: la percepción que se tenga de ella afectará al bienestar subjetivo de manera negativa cuando las personas consideran que su estado de salud o "enfermedad" no les permite alcanzar sus metas más trascendentes.

Dinero: no se ha comprobado que a un mayor nivel de ingresos en un país, proporcionalmente, se alcancen mayores niveles de bienestar.

De modo que se hace importante el desarrollo e incremento del bienestar. Por ello, en la siguiente sección se analizan algunas propuestas.

Evidentemente, el bienestar juega un rol importante como facilitador de otros procesos psicológicos positivos. Desde la medición psicológica científica actual, esto es indudable, sin embargo, ¿cuánto mejoraría la experiencia del bienestar y los procesos a esta vinculados si se consideraran los principios bíblicos y si se pusiera a Dios en primer lugar? Esta pregunta surge considerando el texto de Mateo 6:3 que señala "Mas buscad primeramente el reino de Dios y su justicia y todas estas cosas os serán añadidas".

\section{Fomentar el bienestar}

Fordyce (1983) uno de los pioneros en realizar experimentos controlados dirigidos a la mejora de la felicidad y el bienestar, propone 14 reglas fundamentales del programa cognitivo conductual:

- Mantenerse más activo y ocupado: en actividades placenteras, actividades físicas, actividades novedosas, actividades con compañía y que tengan sentido.

- Emplear tiempo en actividades sociales.

- Ser productivo en trabajos a los que se dé un significado.

- Organizarse, manejar bien el tiempo.

- Detener preocupaciones.

- Ajustar expectativas y aspiraciones.

- Desarrollar un estilo de pensamiento optimista y positivo.

- Centrarse en el presente más que preocuparse por el pasado o el futuro.

- Desarrollar una personalidad saludable.

- Desarrollar una personalidad sociable y con actividades fuera de casa.

- Ser auténtico.

- Eliminar sentimientos negativos y problemas.

- Fomentar y conservar relaciones íntimas.

- Valorar la felicidad y su mantenimiento.

Aunque de estas propuestas son valiosas y resultan interesantes, desde la cosmovisión bíblica, se añade el creer en Dios como creador, sustentador y salvador, y el respeto a sus leyes y principios, lo cual asegura el bienestar en todas sus áreas (CSI, 203).

Otras actividades que favorecen al bienestar se desprenden de la descripción de las áreas física, mental, social y espiritual presentadas anteriormente.

\section{CONCLUSIONES Y RECOMENDACIONES}

Se concluye que el estudio del bienestar es de importancia por el rol nuclear que juega en la existencia del ser humano. El estudio del mismo ha generado una serie de explicaciones que confluyen en la subjetividad de quien lo experimenta, usando como razón la propia interpretación o juicio de bienestar y basado en criterios como el desarrollo personal, la vida placentera, la satisfacción de las necesidades psicológicas básica o mantenerse activo y ocupado. Aunque todo ello puede contribuir al "estar bien", existe una carencia de una perspectiva trascendente que vincule al ser humano con su Creador y en la presencia de estándares claramente definidos que generan el bienestar como son los mandamientos y el respeto a Dios. 
El concepto bíblico del bienestar presenta a un Dios interesado el bienestar humano, con claros propósitos de proveer un bienestar presente y eterno. Además, en la experiencia del bienestar es integral, implicando las áreas física, mental, social y espiritual; las mismas que resulta del cultivo de pensamientos, actitudes y conductas que estén en concordancia con las leyes divinas. Solo de esta manera todo hombre y mujer podrá gozar de un pleno bienestar en todas sus dimensiones. Además que el bienestar experimentado en la vida terrenal bajo los principios de Dios son una antesala del verdadero bienestar eterno el cual debe procurar.

Se recomienda el desarrollo de futuros trabajos que permitan profundizar aún más la comprensión de los aspectos positivos de la experiencia humana, tanto desde el punto de vista teórico o bíblico filosófico, empírico. Aspectos tales como el bienestar infantil y de los estudiantes, ahondar en la comprensión de las emociones positivas en relación al matrimonio en yugo igual y al reposo sabático y a la vida espiritual.

\section{REFERENCIAS BIBLIOGRÁFICAS}

Asili, P. N. y Pinzón, B.K. (2003). Relación entre estilos parentales, estilos de apego y bienestar psicológico. Psicología y Salud, 13(2), 215-225

Casullo, M., Castro, A. (2000). Evaluación del Bienestar psicológico en estudiantes adolescentes argentinos. Facultad de Psicología. Universidad de Buenos Aires.

Carr, A. (2007). Psicología positiva. España: Paidós Ibérica

Chávez, A. (2006). Bienestar psicológico y su influencia en el rendimiento académico de estudiantes de nivel medio superior. (Tesis de Maestría en Psicología Aplicada, Universidad de Colima)

Deci y Ryan (1985). The General Causality Orientations scale: Selfdetermination in Personality. Journal of Research in Personality, 19, 109-134.

Deci, E. y Ryan, R. (2000). The "What" and "Why" of Goal Pursuits. Psicological Inquiry, 11, 227-268.

Diener, E. (1994). Assessing Subjective Well-being: Progress and Opportunities. Social Indicators Research, 31, 103-157. Recuperado el 26 de mayo del 2010 de http://www.psych.illinois.edu/ ediener/ publication.html

Fierro, A. (2006). Bienestar personal, adaptación social y factores de personalidad: Estudios con las Escalas Eudemon. Clínica y Salud, 17(3)

Figueroa, M., Contini, N., Lacunza, B., Levín, M. y Estévez, M. (2005). Las estrategias de afrontamiento y su relación con el nivel de bienestar psicológico. Un estudio con adolescentes de nivel socioeconómico bajo de Tucumán (Argentina). Anales de Psicología, 21(1), 66-72. Recuperado el 20 de mayo del 2010 de http://www.um.es/ analesps/v21/v21_1/08-21_1.pdf
Fordyce (1983). A Program to Increase Happiness: Futher Studies. Journal Of Counseling Psychology, 30(4), 483-498

García, C. (2004). Construcción y validación de una técnica para evaluar el bienestar psicológico. (Tesis inédita de doctorado, Instituto Superior de Ciencias Médicas de la Habana, Cuba). Recuperado de http://promociondeeventos.sld.cu/psicosalud/ files/2008/03/resumen-tesis-carmen-reginavictoria.pdf

Gómez, V., Villegas de Posada, C., Barrera, F. y Cruz, J. (2007). Factores predictores de bienestar subjetivo en una muestra colombiana. Revista Latinoamericana de Psicología, 59(2), 311-325. Recuperado el 30 de junio de 2010 de http:// pepsic.bvs-psi.org.br/scielo.php?script $=$ sci arttext\&pid=S0120-05342007000200008\&lng=pt \&nrm=iso

González, R., Montoya, I., Casullo, M. y Bernabéu, J. (2002). Relación entre estilos y estrategias de afrontamiento y bienestar psicológico en adolescentes. Psicothema, 14(2), 363-368.

Nichol, F. (1985). Comentario Bíblico Adventista del Séptimo Día (t4). Idaho: Publicaciones Interamericanas, Boise

Ryff, C. (1989). Happiness is Everything, or is it. Exploration On the Meaning of Psychological Well-Being. Journal of Personality and Social Psychology, 57,(6), 1069-1081. Recuperado del 01 de Julio de 2010 de http://education. ucsb.edu/janeconoley/ed197/documents/ ryffHappinessiseverythingorisit.pdf

Seligman, M. (2003). La auténtica felicidad. Barcelona: Plaza ediciones. 
Valenzuela, R. (2005). Valores y bienestar subjetivo en estudiantes voluntarios de una universidad privada de Lima. (Tesis inédita de licenciatura, Universidad Católica del Perú). Recuperado de http://tesis.pucedu. pe/repositorio/bitstream/handle/123456789/616/ VALENZUELA GARC $\% \mathrm{C} 3 \% 8 \mathrm{DA}$ RAFAEL VAL ORE S $\% \overline{2} 0$ Y $\% 20$ BIENESTAR $\% 20$ SUBJETIVO.pdf? sequence $=1$

Vásquez, C. Montgomery, W. y Montero, V. (2008). Bienestar psicológico, asertividad y rendimiento académico en estudiantes universitarios sanmarquinos. Revista de Investigación Psicológica, 11(2), 139-152. Recuperado el 20 de mayo de 2010 de http://www.scielo.org.pe/scielo.php?script=sci abstract\&pid=S1609-74752008000200009\&lng=es \&nrm $=\mathrm{iso \& t}$ tlng=es

Villarrubia, I., García, M. y Rollá, C. (2005). Relación entre la satisfacción familiar, el bienestar psicológico y el sentido de la vida. Educación y futuro: Revista de Investigación Aplicada y Experiencias Educativas, 12, 141-150

White, E. (1957). Hechos de los apóstoles. [Versión electrónica]. USA: Pacific Press Publishing Association

White, E. (1932). Testimonios selectos. [Versión electrónica]. Buenos Aires: ACES

White, E. (1955). El deseado de todas las gentes. [Versión electrónica]. USA: Pacific Press Publishing Association

White, E. (1959). Ministerio de curación. [Versión electrónica]. USA: Pacific Press Publishing Association

White, E. (1964). Conducción del niño. [Versión electrónica]. USA: Pacific Press Publishing Association

White, E. (1969). El conflicto inminente. [Versión electrónica]. USA: Pacific Press Publishing Association
White, E. (1970). Consejos sobre mayordomía cristiana. [Versión electrónica]. USA: Pacific Press Publishing Association

White, E. (1971). Consejos para los maestros. [Versión electrónica]. USA: Pacific Press Publishing Association

White, E. (1975). Consejos sobre el régimen alimenticio. [Versión electrónica]. Publicaciones interamericanas

White, E. (1975). Educación Cristiana. [Versión electrónica]. Publicaciones interamericanas

White, E. (1987). Cartas a jóvenes enamorados. [Versión electrónica]. Miami: Asociación Publicadora Interamericana

White, E. (1988). Exaltad a Jesús. [Versión electrónica]. USA: Pacific Press Publishing Association

White, E. (1989). Consejos sobre la salud. [Versión electrónica]. Miami: Asociación Publicadora Interamericana

White, E. (1993). Camino a Cristo. [Versión electrónica]. USA: Pacific Press Publishing Association

White, E. (1998). Testimonios para la iglesia. [Versión electrónica]. Miami: Asociación Publicadora Interamericana

White, E. (2004). Joyas de los testimonios. [Versión electrónica]. Buenos Aires: ACES

White, E. (2004). Ser semejante a Jesús. [Versión electrónica]. Buenos Aires: ACES

White, E. (2007). Hogar cristiano. [Versión electrónica]. Buenos Aires: ACES

White, E. (2007). Mente, carácter y personalidad. [Versión electrónica]. Apia

White, E. (2009). Educación. [Versión electrónica]. Miami: Asociación Publicadora Interamericana 